\title{
Influência da densidade do solo em atributos da parte aérea e sistema radicular de crotalária ${ }^{1}$
}

Leandro Pereira Pacheco², Andressa Selestina Dalla Côrt São Miguel ${ }^{2}$, Edna Maria Bonfim-Silva ${ }^{2}$, Edicarlos Damacena de Souza ${ }^{2}$, Francine Damian da Silva ${ }^{2}$

\begin{abstract}
Influence of soil bulk density on

shoot and root traits of crotalaria

The selection of cover crop species with high potential for root growth in dense layers of soil can help in the management of agricultural systems through biological soil unpacking. This study aimed at evaluating the performance of crotalaria species (Crotalaria juncea, C. spectabilis and C. ochroleuca) as unpacking agents, in a dystrophic Oxisol under different bulk densities (1.0 $\mathrm{Mg} \mathrm{m}^{-3}, 1.2 \mathrm{Mg} \mathrm{m}^{-3}, 1.4 \mathrm{Mg} \mathrm{m}^{-3}, 1.6 \mathrm{Mg} \mathrm{m}^{-3}$ and $\left.1.8 \mathrm{Mg} \mathrm{m}^{-3}\right)$. All species showed reduction in the growth of shoots and roots, when cultivated in soil with bulk density higher than $1.4 \mathrm{Mg} \mathrm{m}^{-3}$. Crotalaria juncea showed the best results for shoot and root biomass production with bulk density up to $1.4 \mathrm{Mg} \mathrm{m}^{-3}$. The root growth of plants is higher in layers above and below the compacted layer.
\end{abstract}

KEY-WORDS: Crotalaria juncea; Crotalaria spectabilis; Crotalaria ochroleuca; root development.

\section{INTRODUÇÃO}

O Cerrado brasileiro consolidou-se como importante região agrícola, com destaque para a produção de grãos (Conab 2014). Os solos predominantes nessa região são os Latossolos, que se destacam pelo relevo plano ou suave ondulado, o que favorece os sistemas de produção em larga escala, por meio da mecanização.

Esses solos têm por característica a baixa fertilidade natural. Entretanto, essa condição desfavorável aos cultivos pode ser corrigida com o uso adequado de calagem, gessagem e adubação.

Embora os Latossolos apresentem excelentes propriedades físicas, o seu inadequado manejo, por meio do revolvimento e do trânsito de máquinas agrícolas de forma intensiva, tem favorecido sua compactação (Valicheski et al. 2012).

\section{RESUMO}

A seleção de espécies de plantas de cobertura com potencial para elevado crescimento radicular, em camadas adensadas no solo, pode contribuir para o manejo de sistemas agrícolas, por meio da descompactação biológica do solo. Objetivou-se avaliar o desempenho de espécies de crotalária (Crotalariajuncea, C. spectabilis e C. ochroleuca) como agentes de descompactação, em um Latossolo Vermelho distrófico submetido a diferentes níveis de densidade $\left(1,0 \mathrm{Mg} \mathrm{m}^{-3}\right.$; 1,2 $\mathrm{Mg} \mathrm{m}^{-3} ; 1,4 \mathrm{Mg} \mathrm{m}^{-3} ; 1,6 \mathrm{Mg} \mathrm{m}^{-3}$; e $1,8 \mathrm{Mg} \mathrm{m}^{-3}$ ). Todas as espécies apresentaram redução no crescimento da parte aérea e radicular a partir de $1,4 \mathrm{Mg} \mathrm{m}^{-3}$ de densidade do solo. Crotalaria juncea apresentou os melhores resultados, quanto à produção de fitomassa aérea e de raízes, em níveis de compactação do solo de até $1,4 \mathrm{Mg} \mathrm{m}^{-3}$. O crescimento radicular das plantas é maior nas camadas acima e abaixo da camada compactada.

PALAVRAS-CHAVE: Crotalaria juncea; Crotalaria spectabilis; Crotalaria ochroleuca; desenvolvimento radicular.

O solo compactado apresenta redução na quantidade de macroporos e elevação em sua densidade, o que resulta em menor infiltração de água e aumento na predisposição à erosão hídrica (Foloni et al. 2006). Além disso, desfavorece o aprofundamento do sistema radicular das culturas, com resultados prejudiciais ao crescimento das plantas, principalmente em situações de ocorrência de déficit hídrico (Gonçalves et al. 2006). Ademais, grande parte dos produtores ainda não promove a rotação de culturas e o uso de plantas de cobertura, durante a entressafra. Essas plantas possuem elevado crescimento radicular, permitindo a descompactação biológica do solo (Gonçalves et al. 2006).

Nesse contexto, a difusão do sistema plantio direto (SPD) tem sido realizada no Cerrado, para minimizar os efeitos negativos ao solo promovidos por sistemas agrícolas mais intensivos. A seleção de 
espécies de plantas de cobertura com potencialidades para elevado crescimento radicular, em camadas compactadas do solo, pode melhorar o desempenho dos sistemas agrícolas, por meio da descompactação biológica do solo (Bonfim-Silva et al. 2012).

Debiasi et al. (2010) observaram que o uso de plantas de cobertura é eficiente em reduzir a compactação superficial em solos agrícolas. Gonçalves et al. (2006) concluíram que o milheto (Pennisetum glaucum) e o amaranto (Amaranthus cruentus) se destacaram na produção de fitomassa seca e crescimento radicular, em camadas compactadas. $\mathrm{O}$ crescimento intenso de raízes através do perfil do solo favorece a formação de canais naturais, estimulando o crescimento radicular das culturas em sucessão (Bonfim-Silva et al. 2012).

As plantas de cobertura conhecidas como crotalárias (Crotalaria spp.) têm sido adotadas por parte dos produtores rurais do Cerrado, nos últimos anos. As crotalárias apresentam elevada tolerância ao estresse hídrico, quando semeadas na época da safrinha (fevereiro a abril), reduzem a multiplicação de fitonematoides no solo e proporcionam significativo acúmulo de fitomassa e nutrientes na parte aérea. Destaca-se, também, sua grande capacidade de incorporar nitrogênio ao sistema agrícola, por meio da fixação biológica. Resultados preliminares também têm demonstrado alto potencial da espécie C. juncea em promover a descompactação do solo (Foloni et al. 2006).

Objetivou-se avaliar o desempenho de espécies de crotalária como agentes biológicos de descompactação de solos.

\section{MATERIAL E MÉTODOS}

O experimento foi realizado em casa-de-vegetação, na Universidade Federal de Mato Grosso, em Rondonópolis (MT) (16²7'50,43”S, 54³4'49,39'W e altitude de $289 \mathrm{~m}$ ), de 03 de julho a 20 de novembro de 2013.

O solo utilizado originou-se de uma área sob vegetação de Cerrado, tendo sido coletado na camada de 5-20 $\mathrm{cm}$ de profundidade e classificado como Latossolo Vermelho distrófico (Embrapa 2013). A caracterização química e granulométrica foi realizada de acordo com a Embrapa (1997): $\mathrm{pH}\left(\mathrm{CaCl}_{2}\right)=4,1$; $\mathrm{Al}$ trocável $\left(\mathrm{cmol}_{\mathrm{c}} \mathrm{dm}^{-3}\right)=1,1 ; \mathrm{H}+\mathrm{Al}\left(\mathrm{cmol}_{\mathrm{c}} \mathrm{dm}^{-3}\right)=$ 6,8; $\mathrm{Ca}\left(\mathrm{cmol}_{\mathrm{c}} \mathrm{dm}^{\mathrm{c}}\right)=0,3 ; \mathrm{Mg}\left(\mathrm{cmol}_{\mathrm{c}} \mathrm{dm}^{-3}\right)=0,2$; $\mathrm{P}\left(\right.$ Mehlich 1) $\left(\mathrm{mg} \mathrm{dm}{ }^{-3}\right)=2,4 ; \mathrm{K}\left(\mathrm{cmol}_{\mathrm{c}} \mathrm{dm}^{-3}\right)=0,07$;
$\mathrm{S}\left(\mathrm{mg} \mathrm{dm}^{-3}\right)=6,8$; matéria orgânica $\left(\mathrm{g} \mathrm{dm}^{-3}\right)=22,7$; $\mathrm{V}(\%)=6,5$; Argila $\left(\mathrm{g} \mathrm{kg}^{-1}\right)=367$; Areia $\left(\mathrm{g} \mathrm{kg}^{-1}\right)=$ 549; e Silte $\left(\mathrm{g} \mathrm{kg}^{-1}\right)=84$.

O solo foi peneirado, umedecido e submetido a calagem, 60 dias antes da instalação do experimento, para elevação da saturação por bases a $60 \%$, com aplicação do calcário Filler (PRNT 99,3 \%), na quantidade relativa a $4 \mathrm{t} \mathrm{ha}^{-1}$. A umidade do solo foi mantida a $70 \%$ da capacidade de campo. O delineamento experimental utilizado foi o de blocos inteiramente casualizados, em esquema fatorial $(3 \times 5)$, com quatro repetições. Os tratamentos consistiram de três espécies da família Fabaceae [Crotalaria juncea (L.), C. spectabilis (Roth.) e C. ochroleuca (Meisn)] e cinco níveis de densidade do solo $\left(1,0 \mathrm{Mg} \mathrm{m}^{-3}\right.$; $1,2 \mathrm{Mg} \mathrm{m}^{-3} ; 1,4 \mathrm{Mg} \mathrm{m}^{-3} ; 1,6 \mathrm{Mg} \mathrm{m}^{-3}$; e 1,8 $\left.\mathrm{Mg} \mathrm{m}^{-3}\right)$.

Três anéis de policloreto de vinila (PVC) com $150 \mathrm{~mm}$ de diâmetro e $100 \mathrm{~mm}$ de altura cada foram sobrepostos e unidos por fita adesiva (Silver Tape; $48 \mathrm{~mm} \times 50 \mathrm{~mm}$ ), com o anel inferior aparado por uma tela antiafídeos afixada com anel de borracha, obtido por meio de corte transversal de câmara de ar e acomodado em prato plástico. Os anéis inferiores (correspondentes à camada de 20-30 cm de profundidade) e superiores (correspondentes à camada de 0-10 $\mathrm{cm}$ de profundidade) foram preenchidos com solo, na densidade de $1,0 \mathrm{Mg} \mathrm{m}^{-3}$, sendo a camada intermediária (10-20 $\mathrm{cm}$ de profundidade) compactada para obtenção das densidades de solo, por meio do uso de uma prensa hidráulica (Charlott PH5T), conforme metodologia descrita por Silva et al. (2006).

Foram semeadas oito sementes por unidade experimental, sendo realizado o desbaste sete dias após a semeadura, permanecendo, assim, três plantas por unidade experimental. As parcelas receberam fertilizante formulado $\mathrm{N}: \mathrm{P}_{2} \mathrm{O}_{5}: \mathrm{K}_{2} \mathrm{O}$ (04-14-8), na quantidade de $300 \mathrm{mg} \mathrm{dm}^{-3}$ de solo. Nos primeiros 30 dias após a semeadura, a irrigação ocorreu na superfície do anel superior de PVC e no prato plástico, em razão da necessidade de proporcionar condições adequadas ao estabelecimento das plantas nos primeiros estádios de crescimento. Todavia, a partir desse período, a irrigação foi realizada apenas nos pratos plásticos, a fim de estimular o crescimento radicular das espécies através das camadas de solo compactadas (Silva et al. 2006).

Aos 48 dias após a semeadura, foi realizada a avaliação da altura de plantas $(\mathrm{cm})$, com o uso de régua graduada. Em seguida, efetuou-se o corte das plantas rente ao solo, para contagem do número de 
folhas, e lavagem do sistema radicular nos anéis de PVC com solo (superior, intermediária e inferior), para quantificar o volume radicular e a fitomassa radicular. O volume radicular foi obtido por meio do uso de proveta graduada, em que o sistema radicular de cada anel de PVC foi mergulhado na proveta parcialmente preenchida com água, o que resulta no deslocamento do líquido, expresso $\mathrm{em}^{\mathrm{cm}^{3}}$ (Basso 1999). A fitomassa radicular e foliar foram obtidas via secagem dos tecidos em estufa de circulação forçada, a $65^{\circ} \mathrm{C}$, por aproximadamente 72 horas. Em seguida, foram realizadas a pesagem e a transformação dos dados para g de raízes.

A área foliar foi estimada por meio indireto, no qual retirou-se uma amostra de folhas de cada tratamento, procedeu-se ao cálculo da área foliar com o auxílio de um medidor de área foliar de bancada (Li-3100) e, em seguida, obteve-se o peso seco da amostra medida. Dessa forma, com a fitomassa seca total de folhas, fitomassa e área foliar da amostra de cada tratamento, calculou-se a área foliar de cada tratamento por meio de regra de proporção, expressa em cm² (Amaral 2002).

Todos os resultados foram submetidos à análise de variância. Detectado o efeito das espécies $(\mathrm{p}<0,05)$, as médias foram comparadas pelo teste Tukey, com o uso do programa Sisvar (Ferreira 2008). Para os efeitos significativos de densidade do solo, as médias foram submetidas à análise de regressão, por meio do programa Sigma Plot 10.0 (SPSS, Chicago, IL.).

\section{RESULTADOS E DISCUSSÃO}

Houve efeito da espécie e níveis de densidade do solo para todas as variáveis analisadas, exceto para o volume de raízes na camada intermediária, o qual não variou com a espécie (Tabela 1). Houve interação entre espécie e níveis de densidade para fitomassa seca de caule, número de folhas, fitomassa seca de raiz na camada superior, volume de raízes na camada inferior, fitomassa seca total da parte aérea, fitomassa total da raiz e volume radicular total (Tabela 1).

A Crotalaria juncea destacou-se em todas as variáveis biométricas analisadas (Tabela 2). É importante destacar que ela é reconhecida como uma das espécies de leguminosa de mais rápido crescimento inicial. Essa precocidade intrínseca pode ter favorecido seu desempenho, uma vez que o experimento foi conduzido até 48 dias após a semeadura. Gitti et al. (2012), ao testarem o consórcio entre milho e espécies de crotalária, observaram que a $C$. juncea apresentou crescimento inicial mais acelerado, em relação à $C$. spectabilis. Observações semelhantes também foram descritas por Teodoro et al. (2011).

A C. juncea caracterizou-se como espécie de porte mais alto, uma vez que a parte aérea apresentou caules mais longos e pesados, com elevado potencial em emitir ramificações (Tabela 2). Embora possua maior número de folhas, em relação à C. spectabilis, suas áreas foliares e fitomassa seca de folhas foram similares. Dessa forma, a maior fitomassa seca total da parte aérea observada para C. juncea está relacio-

Tabela 1. Análise de variância (valores de F) para fitomassa seca da parte aérea (folhas e caules) e radicular, altura de plantas, área foliar e volume radicular de Crotalaria spectabilis, C. juncea e C. ochroleuca submetidas a cinco níveis de densidade do solo (Rondonópolis, MT, 2013).

\begin{tabular}{lccc}
\hline \multicolumn{1}{c}{ Fonte de variação } & Espécie & Nível de densidade (ND) & Espécie x ND \\
\hline Fitomassa seca de folhas $(\mathrm{g})$ & $14,91^{* *}$ & $40,98^{* *}$ & $0,93^{\mathrm{ns}}$ \\
Fitomassa seca de caule $(\mathrm{g})$ & $98,23^{* *}$ & $66,92^{* *}$ & $4,90^{* *}$ \\
Altura $(\mathrm{cm})$ & $193,24^{* *}$ & $68,00^{* *}$ & $1,46^{\mathrm{ns}}$ \\
Área foliar $\left(\mathrm{cm}^{2}\right)$ & $16,60^{* *}$ & $38,43^{* *}$ & $1,25^{\mathrm{ns}}$ \\
Número de folhas & $262,15^{* *}$ & $29,66^{* *}$ & $10,38^{* *}$ \\
Fitomassa seca de raiz $(0-10 \mathrm{~g})$ & $15,73^{* *}$ & $3,78^{* *}$ & $2,53^{*}$ \\
Fitomassa seca de raiz $(10-20 \mathrm{~g})$ & $3,68^{*}$ & $8,74^{* *}$ & $1,10^{\mathrm{ns}}$ \\
Fitomassa seca de raiz $(20-30 \mathrm{~g})$ & $9,49^{* *}$ & $7,60^{* *}$ & $1,23^{\mathrm{ns}}$ \\
Volume radicular $\left(0-10 \mathrm{~cm}^{3}\right)$ & $16,03^{* *}$ & $10,06^{* *}$ & $1,61^{\mathrm{ns}}$ \\
Volume radicular $\left(10-20 \mathrm{~cm}^{3}\right)$ & $0,38^{\mathrm{ns}}$ & $9,86^{* *}$ & $1,36^{\mathrm{ns}}$ \\
Volume radicular $\left(20-30 \mathrm{~cm}^{3}\right)$ & $14,44^{* *}$ & $24,21^{* *}$ & $2,57^{*}$ \\
Fitomassa seca total da parte aérea $(\mathrm{g})$ & $40,02^{* *}$ & $65,79^{* *}$ & $3,98^{*}$ \\
Fitomassa seca total da raiz $(\mathrm{g})$ & $9,96^{* *}$ & $7,01^{* *}$ & $2,39^{*}$ \\
Volume radicular total $\left(\mathrm{cm}^{3}\right)$ & $8,89^{* *}$ & $11,90^{* *}$ & $2,23^{*}$ \\
\hline
\end{tabular}

$*, * * \mathrm{e}^{\text {ns: }}$ significativo a $5 \%$ e a $1 \%$ e não significativo, respectivamente. 
nada a características dos colmos e ramificações. Por outro lado, a C. spectabilis apresentou potencial em compensar o menor número de folhas por meio da maximização do tamanho das folhas.

A C. ochroleuca parece ser uma espécie de crescimento intermediário, o que pode ser atestado pelos resultados apresentados na Tabela 2. Essa espécie possui elevado número de folhas, porém, com tamanhos reduzidos, o que resultou em menor fitomassa seca de folhas. Embora a fitomassa seca total da parte aérea tenha sido similar entre C. spectabilis e C. ochroleuca, a primeira foi a espécie que apresentou a maior proporção de folhas, o que pode resultar em maior velocidade de decomposição e liberação de nutrientes ao solo.

Os resultados sugerem que as crotalárias possuem melhor desenvolvimento da parte vegetativa e radicular quando submetidas a um leve adensamento do solo, corroborando os dados obtidos por Silva et al. (2006). Esses autores verificaram melhor desenvolvimento da parte aérea em milho, algodão e $U$. brizantha, em densidades do solo próximas a 1,2 $\mathrm{Mg} \mathrm{m}^{-3}$. Calonego et al. (2011) concluíram que o adensamento intermediário do solo não reduz a produção de massa seca da parte aérea e radicular de sorgo (Sorghum bicolor), labe-labe (Dolichos lablab) e braquiárias (U. ruziziensis).

A maioria das variáveis analisadas ajustaram-se a uma equação polinomial quadrática, em resposta aos cinco níveis de densidade do solo. Para os dados de produção total de fitomassa seca da parte aérea, as equações polinomiais quadráticas apresentaram sig- nificância para $C$.juncea $(\mathrm{p}<0,05)$ e $C$. ochroleuca $(\mathrm{p}<0,01)$ (Figura 1). As duas espécies apresentaram valores máximos de fitomassa seca total da parte aérea de $1,23 \mathrm{Mg} \mathrm{m}^{-3}$ e $1,19 \mathrm{Mg} \mathrm{m}^{-3}$ de solo, respectivamente. É importante destacar que densidade de solo superior a $1,6 \mathrm{Mg} \mathrm{m}^{-3}$ provoca efeitos mais intensos na redução de fitomassa seca da parte aérea, com significativa restrição ao desenvolvimento aéreo e radicular das plantas. Tais resultados corroboram o estudo de Jimenez et al. (2008), que constataram que o guandu obteve crescimento da parte aérea e radicular limitado, com o aumento da densidade do solo na camada compactada.

Para a fitomassa seca de caule, a C. juncea $(\mathrm{p}<0,05)$ obteve o seu ponto máximo de produção na densidade de solo de $1,22 \mathrm{Mg} \mathrm{m}^{-3}$ e a C. ochroleuca ( $\mathrm{p}<0,01)$ na densidade de $1,11 \mathrm{Mg} \mathrm{m}^{-3}$ (Figura 1). A C. ochroleuca é mais sensível à compactação, por apresentar redução mais acentuada na fitomassa seca de caule nos maiores níveis de densidade do solo, o que resultou na redução da produção de fitomassa seca e altura da parte aérea das plantas (Figura 1). Tais resultados estão de acordo com Foloni et al. (2006), que demonstraram que se a camada compactada subsuperficial inibir o crescimento radicular em profundidade, o desenvolvimento da parte aérea das plantas será dependente da disponibilidade de água e nutrientes do solo da camada superficial. Assim, a absorção de água e nutrientes fica restrita, comprometendo o desenvolvimento vegetativo.

As crotalárias apresentaram redução no número de folhas, com o aumento da densidade do solo

Tabela 2. Fitomassa seca da parte aérea e radicular, altura de plantas, área foliar e volume radicular de Crotalaria spectabilis, C. juncea e C. ochroleuca submetidas a cinco níveis de densidade do solo (Rondonópolis, MT, 2013).

\begin{tabular}{|c|c|c|c|c|}
\hline Fonte de variação & C. spectabilis & C. juncea & & C. ochroleuca \\
\hline Fitomassa seca de folhas (g) & 3,52 a & 3,85 & a & $2,72 \mathrm{~b}$ \\
\hline Fitomassa seca de caule (g) & $1,89 \mathrm{c}$ & 4,60 & a & $3,50 \mathrm{~b}$ \\
\hline Altura (cm) & $48,82 \mathrm{c}$ & 101,98 & a & $71,71 \quad b$ \\
\hline Área foliar $\left(\mathrm{cm}^{2}\right)$ & $1.072,73 \mathrm{a}$ & $1.023,67$ & $\mathrm{a}$ & $739,04 \quad b$ \\
\hline Número de folhas & $25,54 \mathrm{c}$ & 66,68 & $\mathrm{~b}$ & 138,03 a \\
\hline Fitomassa seca de raiz $(0-10 \mathrm{~g})$ & $1,25 \mathrm{~b}$ & 3,03 & a & 2,31 a \\
\hline Fitomassa seca de raiz (10-20 g) & $0,59 \mathrm{~b}$ & 0,90 & $\mathrm{a}$ & $0,62 \mathrm{ab}$ \\
\hline Fitomassa seca de raiz (20-30 g) & $0,82 \quad b$ & 2,15 & $\mathrm{a}$ & $1,13 \quad b$ \\
\hline Volume radicular $\left(0-10 \mathrm{~cm}^{3}\right)$ & $10,55 \mathrm{~b}$ & 17,98 & $\mathrm{a}$ & $16,00 \mathrm{a}$ \\
\hline Volume radicular $\left(10-20 \mathrm{~cm}^{3}\right)$ & 7,78 a & 8,35 & $\mathrm{a}$ & 8,95 a \\
\hline Volume radicular $\left(20-30 \mathrm{~cm}^{3}\right)$ & 8,71 b & 17,46 & $\mathrm{a}$ & 13,90 a \\
\hline Fitomassa seca total da parte aérea $(\mathrm{g})$ & $5,41 \quad b$ & 8,46 & $\mathrm{a}$ & $6,21 \quad b$ \\
\hline Fitomassa seca total da raiz (g) & $2,66 \mathrm{c}$ & 5,46 & $\mathrm{a}$ & $4,08 \mathrm{~b}$ \\
\hline Volume radicular total $\left(\mathrm{cm}^{3}\right)$ & $27,04 \mathrm{c}$ & 43,79 & $\mathrm{a}$ & $38,85 \mathrm{~b}$ \\
\hline
\end{tabular}

Médias seguidas pelas mesmas letras, na coluna, não diferem estatisticamente entre si a $5 \%$, pelo teste Tukey. 
(Figura 2). A C. ochroleuca apresentou maior emissão de número de folhas, o que está associado a condições intrínsecas dessa espécie. Todavia, observa-se que o efeito da compactação do solo na emissão de folhas dessa espécie foi mais acentuado, o que pode ser atestado pelo terceiro componente da equação polinomial $\left(-238,6 x^{2}\right)$. Quanto à área foliar, as crotalárias apresentaram sensível redução, com o aumento da densidade do solo, o que está associado à redução no número e, também, no tamanho das folhas.

A C. juncea apresentou os maiores valores de fitomassa seca de raiz, em relação às demais crotalárias. Tais resultados demonstram que essa espécie, mesmo em condições de compactação do solo, apresenta maior potencial em mitigar esses efeitos nos estágios iniciais de seu crescimento (Figura 3). Todavia, é importante destacar que o aumento na densidade do solo promoveu redução no crescimento radicular em todas as espécies. Essas observações estão alinhadas com resultados descritos por Dezordi et al. (2013), em que o aumento da densidade do solo repercutiu negativamente no desempenho das espécies de milheto (Pennisetum glaucum), U. brizantha e C. spectabilis. Os mesmos autores constataram que densidades acima de $1,4 \mathrm{Mg} \mathrm{m}^{-3}$ são limitantes para o crescimento de raízes dessas espécies. Adicionalmente, é possível que estudos dessa natureza precisem ser realizados de forma regional, uma vez que as características do solo e o clima interferem nos resultados.

Ao analisar a partição do sistema radicular das plantas ao longo do perfil do solo (três profundidades), observou-se que as plantas apresentaram maior
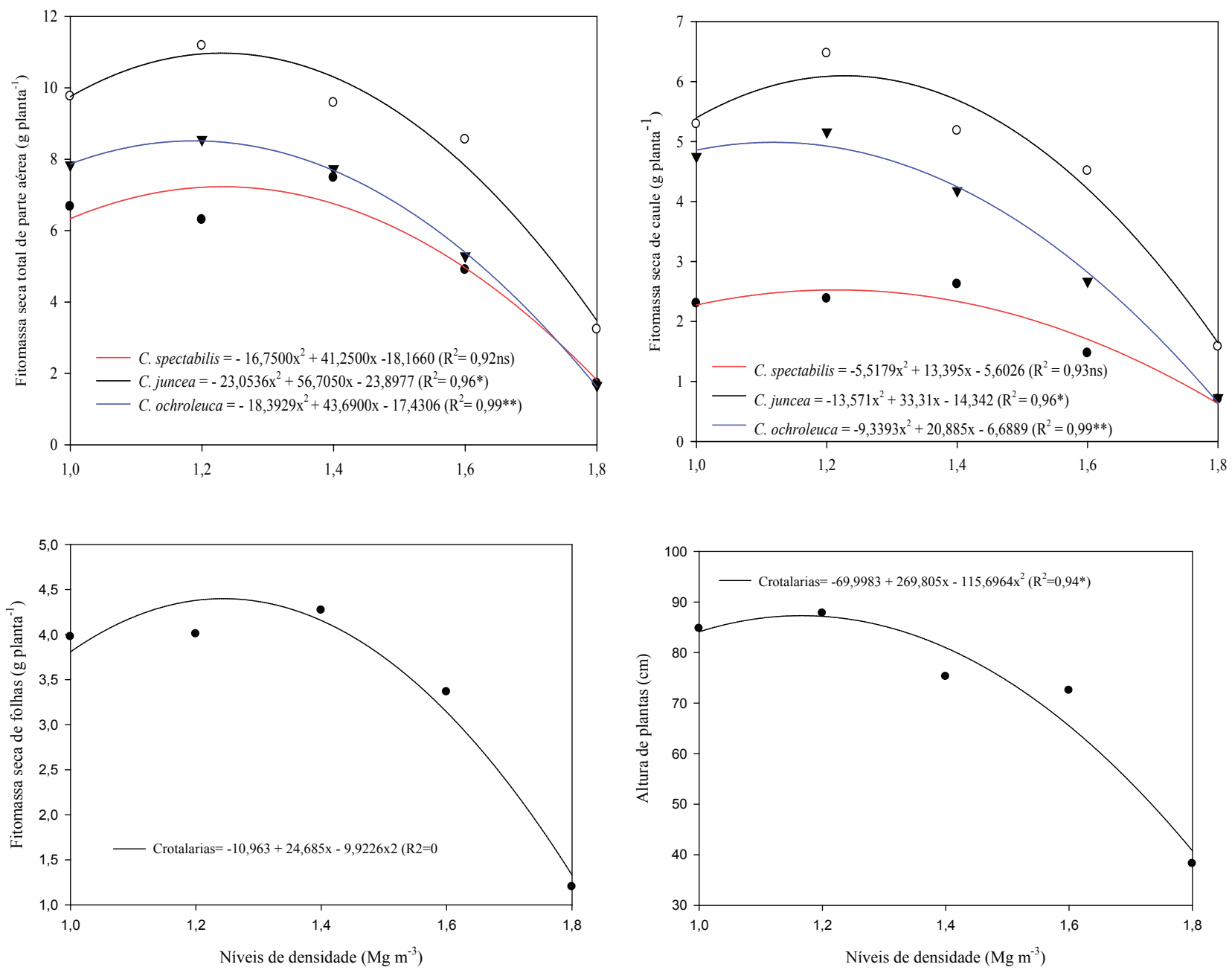

Figura 1. Fitomassa seca de folhas, caules e total de parte aérea e altura de plantas de Crotalaria spectabilis, C.juncea e C. ochroleuca submetidas a cinco níveis de densidade de solo (Rondonópolis, MT, 2013). *, ** e ns: significativo a $5 \%$ e a $1 \%$ e não significativo, respectivamente. 

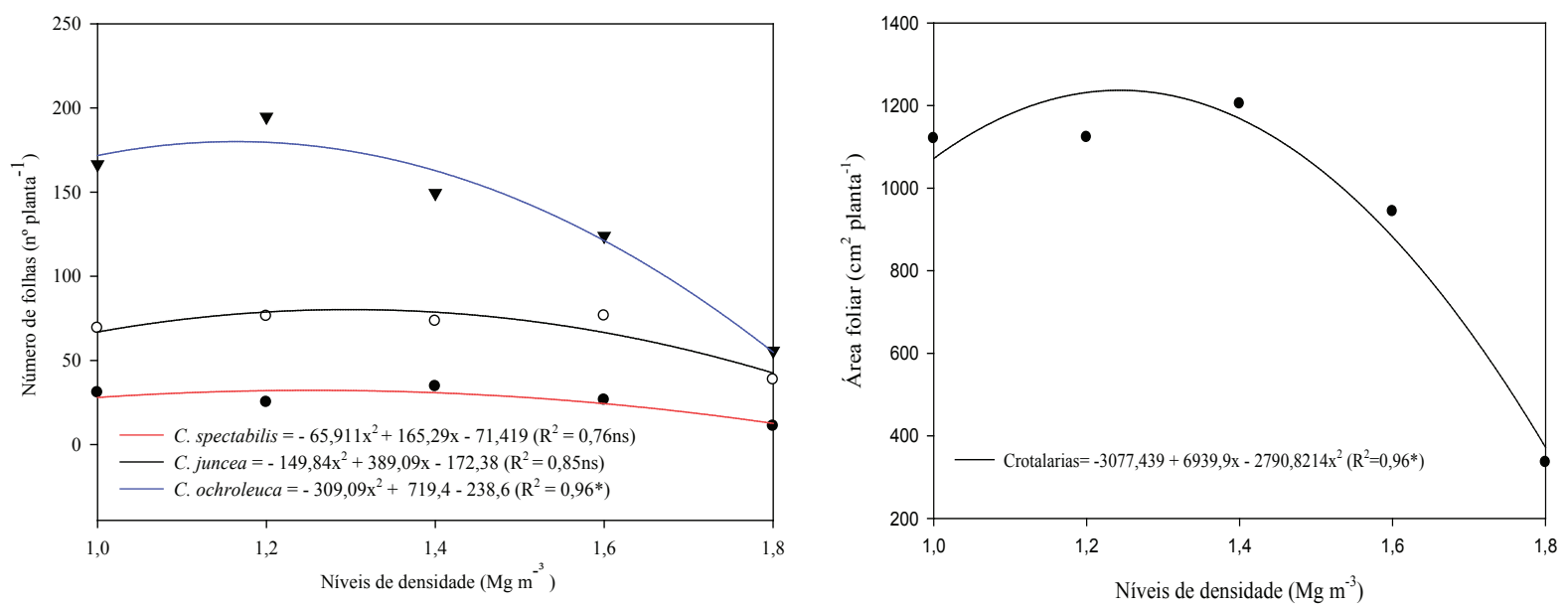

Figura 2. Número de folhas e área foliar de Crotalaria spectabilis, C. juncea e C. ochroleuca submetidas a cinco níveis de densidade de solo (Rondonópolis, MT, 2013). *, ** e ns: significativo a $5 \%$ e a $1 \%$ e não significativo, respectivamente.
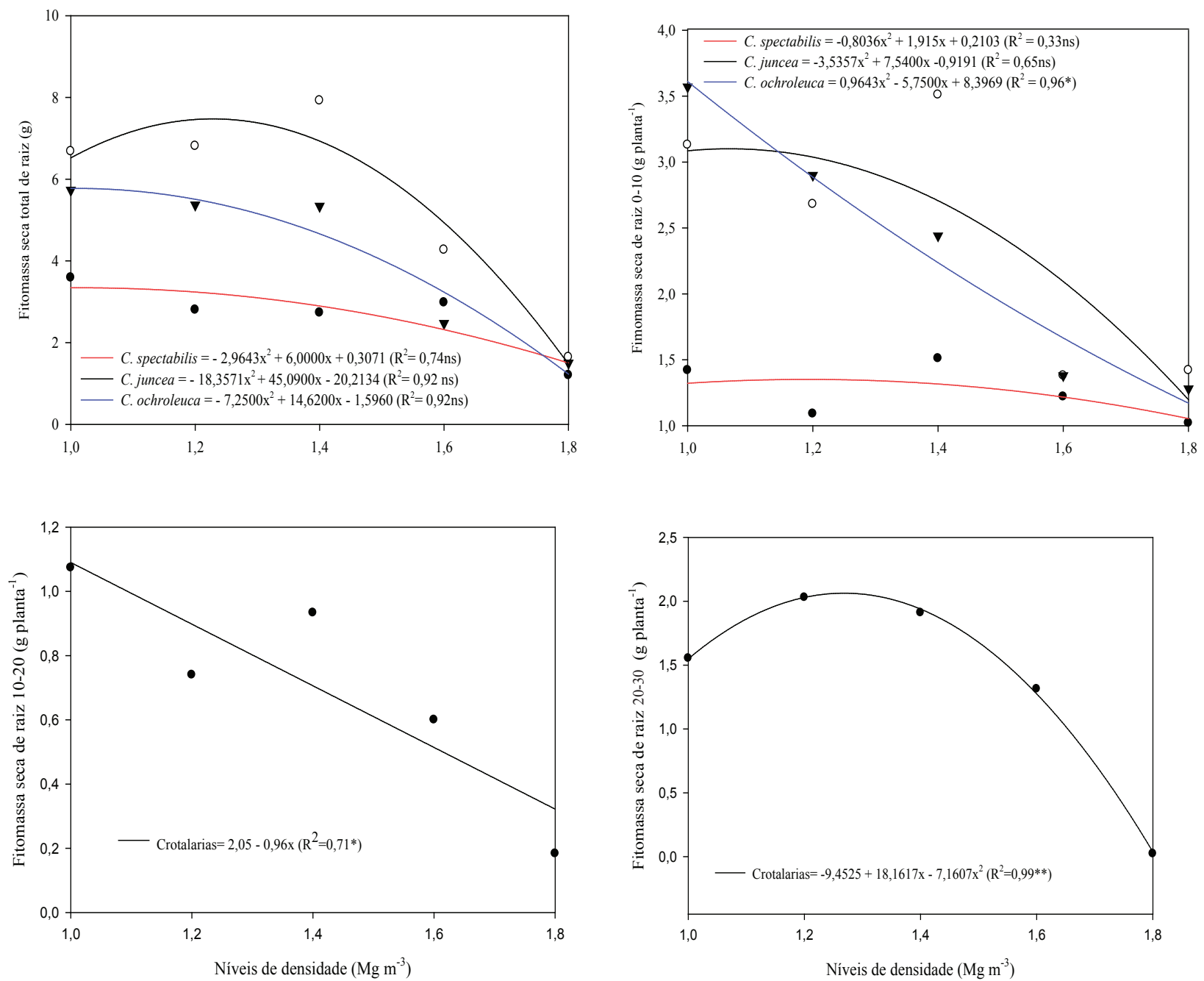

Figura 3. Fitomassa seca total de raiz e fitomassa seca de raiz nos anéis de 0-10 cm, 10-20 cm e 20-30 cm de profundidade de Crotalaria spectabilis, $C$. juncea e C. ochroleuca submetidas a cinco níveis de densidade de solo (Rondonópolis, MT, 2013). *, ** e $\mathrm{e}^{\text {ns: }}$ significativo a $5 \%$ e a $1 \%$ e não significativo, respectivamente. 
presença de raízes nas camadas superficiais $(0-10 \mathrm{~cm})$ e abaixo da camada compactada $(20-30 \mathrm{~cm})$. Esses resultados também foram relatados por Rosolem et al. (1994) e Foloni et al. (2003), com raízes de milho.

A relação entre produção de fitomassa das raízes e da parte aérea foi de aproximadamente $65 \%$, até a densidade $1,6 \mathrm{Mg} \mathrm{m}^{-3}$. Também se constatou que cerca de $20 \%$ das raízes das plantas estavam presentes na camada compactada $(10-20 \mathrm{~cm})$. Assim, é possível estimar que a cada $1.000 \mathrm{~kg} \mathrm{ha}^{-1} \mathrm{de}$ fitomassa de parte aérea produzida pelas crotalárias, são incorporados ao solo $650 \mathrm{~kg} \mathrm{ha}^{-1}$ de fitomassa radicular, inclusive rompendo as camadas adensa- das do solo. Essa relação foi ainda maior quando se utilizou a espécie $C$. juncea.

Quanto ao volume radicular total (Figura 4), a $C$. juncea ajustou-se ao modelo quadrático de regressão, obtendo seu ponto de máxima na densidade de solo de 1,22 $\mathrm{Mg} \mathrm{m}^{-3}$ e, consequentemente, maior acúmulo de fitomassa seca total de raiz. No entanto, houve diminuição significativa no volume radicular, quando comparado o primeiro nível de densidade do solo $\left(1,0 \mathrm{Mg} \mathrm{m}^{-3}\right)$ com o último $\left(1,8 \mathrm{Mg} \mathrm{m}^{-3}\right)$. Essa diferença de volumes ocorreu porque quanto menor a densidade, maior é a proporção de espaço poroso, facilitando o crescimento das raízes e melhorando
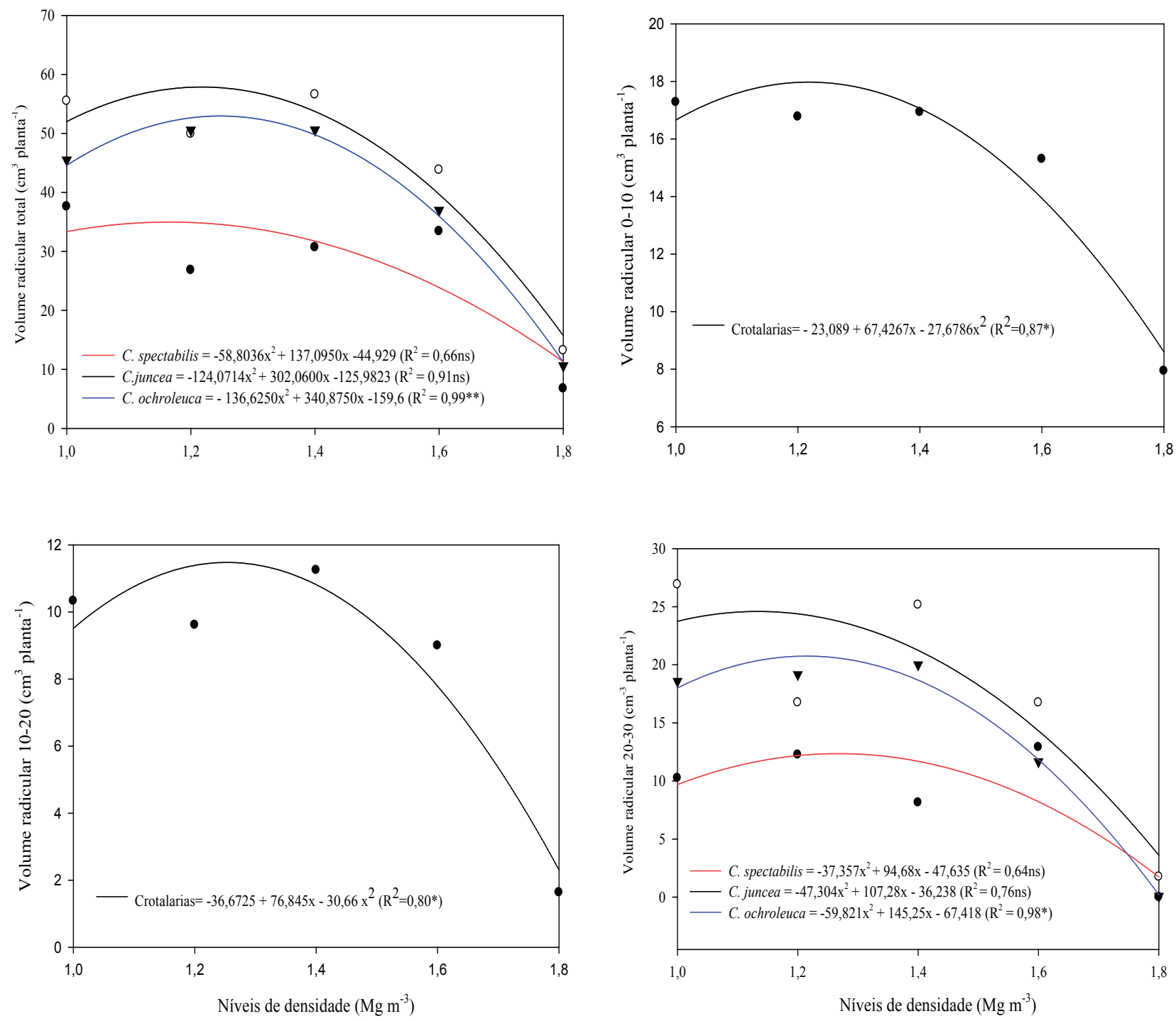

Figura 4. Volume radicular total e volume radicular nos anéis a 0-10 cm, 10-20 cm e 20-30 cm de profundidade de Crotalaria spectabilis, C. juncea e C. ochroleuca submetidas a cinco níveis de densidade de solo (Rondonópolis, MT, 2013). *, ** $\mathrm{e}^{\text {ns: }}$ significativo a $5 \%$ e a $1 \%$ e não significativo, respectivamente. 
a infiltração da água. Por outro lado, nos níveis de maior densidade, a pressão mecânica do solo limitou a penetração das raízes e, com isso, reduziu a absorção de água, nutrientes e o acúmulo de carbono pela fotossíntese, resultando na redução do volume radicular e do acúmulo de fitomassa total da parte aérea. Segundo Moura et al. (2008), isso ocorre quando as condições não são favoráveis às plantas, e resultam em maior gasto de carboidratos para que o crescimento radicular possa atravessar as camadas compactadas.

Para o volume radicular, os resultados da análise de regressão não foram significativos para todas as espécies (Figura 4). Porém, a C. juncea demonstrou resultados consideráveis, visto que apresentou as maiores médias nos três anéis, inclusive à profundidade de 20-30 cm. Os resultados apresentados são condizentes com Foloni et al. (2006), que demonstraram que o aumento da impedância mecânica do solo pode promover a proliferação de raízes secundárias, que são mais finas e, por essa condição, mais eficientes para penetrar nos poros do solo, mesmo naqueles mais argilosos. Essa característica confere à planta um potencial de formar bioporos (Reinert et al. 2008), que, após a morte e decomposição das raízes, formam canais para as raízes da cultura seguinte crescerem. $\mathrm{O}$ aumento da porosidade melhora as condições físicas e microbiológicas do solo, por meio do aumento das trocas gasosas e da infiltração de água (Abreu et al. 2004).

De acordo com Foloni et al. (2003), na camada compactada do solo ocorrem modificações fisiológicas e morfológicas nas raízes, provocando aumento do seu diâmetro por conta da maior resistência mecânica do solo. Com o aumento do diâmetro radicular, ocorre diminuição na absorção de água e nutrientes (Bonfim-Silva et al. 2012). No entanto, Müller et al. (2001) sugerem que um bloqueio do alongamento da região apical pelo adensamento do solo sobre as raízes provém da produção de raízes laterais finas, e não da diminuição propriamente dita do diâmetro das mesmas.

\section{CONCLUSÕES}

1. Todas as espécies de crotalária estudadas apresentam redução no crescimento da parte aérea e raízes a partir da densidade de solo de $1,4 \mathrm{Mg} \mathrm{m}^{-3}$.

2. A espécie Crotalaria juncea apresenta os melhores resultados, quanto à produção de fitomassa da parte aérea e das raízes, nos níveis de compactação do solo, até 48 dias após a semeadura.

3. O crescimento radicular das plantas é maior nas camadas acima e abaixo da camada compactada.

\section{REFERÊNCIAS}

ABREU, S. L.; REICHERT, J. M.; REINERT, D. J. Escarificação mecânica e biológica para a redução da compactação em Argissolo Franco-Arenoso sob plantio direto. Revista Brasileira de Ciência do Solo, Viçosa, v. 28, n. 3, p. 519-531, 2004.

AMARAL, J. F. T. Eficiência de produção de raízes, absorção, translocação e utilização de nutrientes em cultivares de café arábica. 2002. $97 \mathrm{f}$. Tese (Doutorado em Fitotecnia) - Universidade Federal de Viçosa, Viçosa, 2002.

BASSO, S. M. S. Caracterização morfológica e fixação biológica de nitrogênio de espécies de Adesmia DC e Lotus L. 1999. 268 f. Tese (Doutorado em Zootecnia) Universidade Federal do Rio Grande do Sul, Porto Alegre, 1999.

BONFIM-SILVA, E. M. et al. Establishment of Xaraés and Marandu grasses under levels of soil compaction. Revista Engenharia Agrícola, Jaboticabal, v. 32, n. 4, p. 727-735, 2012.

CALONEGO J. C. et al. Desenvolvimento de plantas de cobertura em solo compactado. Bioscience Journal, Uberlândia, v. 27, n. 2, p. 289-296, 2011.

COMPANHIA NACIONAL DE ABASTECIMENTO (Conab). Acompanhamento da safra brasileira de grãos: $10^{\circ}$ levantamento da produção de grãos - safra 2013/14 . Brasília, DF: Conab, 2014.

DEBIASI, H. et al. Produtividade de soja e milho após coberturas de inverno e descompactação mecânica do solo. Pesquisa Agropecuária Brasileira, Brasília, DF, v. 45, n. 6, p. 603-612, 2010.

DEZORDI, G. B. et al. Desenvolvimento aéreo e radicular de espécies vegetais em Latossolo Vermelho distroférrico sob compactação induzida. Revista Scientia Plena, Aracaju, v. 9, n. 5, p. 1-6, 2013.

EMPRESA BRASILEIRA DE PESQUISA AGROPECUÁRIA (Embrapa). Centro Nacional de Pesquisa de Solos. Manual de métodos de análise de solo. 2. ed. Rio de Janeiro: Embrapa, 1997.

EMPRESA BRASILEIRA DE PESQUISA AGROPECUÁRIA (Embrapa). Sistema brasileiro de classificação de solos. 3. ed. Brasília, DF: Embrapa, 2013. 
FERREIRA, D. F. Sisvar: um programa para análises e ensino de estatística. Revista Cientifica Symposium, Lavras, v. 6, n. 1, p. 36-41, 2008.

FOLONI, J. S. S.; CALONEGO, J. C.; LIMA, S. L. Efeito da compactação do solo no desenvolvimento aéreo e radicular de cultivares de milho. Pesquisa Agropecuária Brasileira, Brasília, DF, v. 38, n. 8, p. 947-953, 2003.

FOLONI, J. S. S.; LIMA, S. L.; BULL, L. T. Crescimento aéreo e radicular da soja e de plantas de cobertura em camadas compactadas de solo. Revista Brasileira de Ciência do Solo, Viçosa, v. 30, n. 1, p. 49-57, 2006.

GITTI, D. C. et al. Épocas de semeadura de crotalária em consórcio com milho. Revista Brasileira de Milho e Sorgo, Sete Lagoas, v. 11, n. 2, p. 156-158, 2012.

GONÇALVES, W. G. et al. Sistema radicular de plantas de cobertura sob compactação do solo. Revista Engenharia Agrícola, Jaboticabal, v. 26, n. 1, p. 67-75, 2006.

JIMENEZ, R. L. et al. Crescimento de plantas de cobertura sob diferentes níveis de compactação em um Latossolo Vermelho. Revista Brasileira de Engenharia Agrícola e Ambiental, Campina Grande, v. 12, n. 2, p. 116-121, 2008.

MOURA, P. M. de et al. Efeito da compactação em dois solos de classes texturais diferentes na cultura do rabanete. Revista Caatinga, Mossoró, v. 21, n. 5, p. 107-112, 2008.

MÜLLER, M. M. L.; CECCON, G.; ROSOLEM, C. A. Influência da compactação do solo em subsuperfície sobre o crescimento aéreo e radicular de plantas de adubação verde de inverno. Revista Brasileira de Ciência do Solo, Viçosa, v. 25, n. 3, p. 531-538, 2001.

REINERT, D. J. et al. Limites críticos de densidade do solo para o crescimento de raízes de plantas de cobertura em Argissolo Vermelho. Revista Brasileira de Ciência do Solo, Viçosa, v. 32, n. 5, p. 1805-1816, 2008.

ROSOLEM, C. A. et al. Sistema radicular e nutrição do milho em função da calagem e da compactação do solo. Revista Brasileira de Ciência do Solo, Viçosa, v. 18, n. 3, p. 491-497, 1994.

SILVA, G. J.; MAIA, J. C. S.; BIANCHINI, A. Crescimento da parte aérea de plantas cultivadas em vaso, submetidas à irrigação subsuperficial e a diferentes graus de compactação de um Latossolo Vermelho-Escuro distrófico. Revista Brasileira de Ciência do Solo, Viçosa, v. 30, n. 1, p. 31-40, 2006.

TEODORO, R. B. et al. Aspectos agronômicos de leguminosas para adubação verde no Cerrado do Alto Vale do Jequitinhonha. Revista Brasileira de Ciência do Solo, Campinas, v. 35, n. 2, p. 635-643, 2011.

VALICHESKI, R. R. et al. Desenvolvimento de plantas de cobertura e produtividade da soja conforme atributos físicos em solo compactado. Revista Brasileira de Engenharia Agrícola e Ambiental, Campina Grande, v. 16, n. 9, p. 969-977, 2012. 